Nova Southeastern University

From the SelectedWorks of Debra Moss (Curtis) Vollweiler

April, 2017

\title{
"No Shots, No School, No Kidding": The Legal Profession Needs A Vaccine To Ensure Professionalism
}

Debra Moss Curtis 


\section{$:$ \\ UNIVERSITY OF FLORIDA \\ JOURNAL OF LAW \& PUBLIC POLICY}

\section{ARTICLES}

"No Shots, No School, No Kidding": The Legal

Profession Needs a Vaccine to

Ensure Professionalism

Debra Mass Curtis

Reimagining Accountability: A Move Toward

Re-Entrenching the Higher Education Act

Twinette L. Johnson

Preventing "Going Dark": A Sober Analysis and

Reasonable Solution to Preserve Security in the ENCRYPTION DEBate

Eric Manpearl

Reducing the Civil "Justice Gap" by Enhancing the

Delivery of Pro Bono Legal Assistance to

Indigent Pro Se Litigants: A "Field"

ASSESSMENT AND RECOMMENDATIONS

Andrew H. Cohn

Utilizing Florida's Stance on Domestic Violence

Laws Regarding Same-Sex Couples as an

EfFective Model for National Uniformity

Sara Qureshi

NOTIS

Crypto-Currencies: The 21 st Century's Money

Laundering and Tax Havens

Edgar G. Sánchez

Restorative Justice in the Context of Intimate

Partner Violence: Suggestions for its Qualified

Usage as Supplementary to the Criminal

JUSTICE SYSTEM

Avila Stahlman

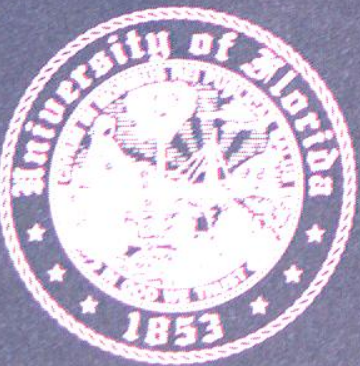

\begin{tabular}{lll} 
Vol. 28 & 2017 & Issue 1 \\
\hline
\end{tabular} 


\section{University of Florida \\ Journal of Law and Public Policy}

\section{Head Research Editor} JACK HACKETT

Executive Research Editors CAROLINA CALVO DYLAN SCHOTT AVILA STAHLMAN

\section{Assistant Editor-in-Chief} MEGHAN BRADLEY

Faculty Advisor TERESA J. REID

Senior Research Editors KRISTIN BABIK KYLIE BROWN LINDSEY LAMB ERIC WATSON

Executive Notes Chair KEVIN TRAGESSER

TRAVIS ALLEN

DEANNA ANDREWS

FARIS ASHOURI

KRISTIN BABIK

ABE ANDREW BAILEY

MICHAEL BOYNTON

TIFFANY BREUER

CHRIS BUCALO

ALYXANDRA BUHLER JEFFREY CAISSE MARIA CASTRO BRANDON COOK BRITTANY CROSS

CHRISTINE CSENCSITZ JOHN DARNELLL

\section{Editorial Board}

Editor in Chief

BIANCA MANOS

Managing Editor MEgAN RUSCELLO

Senior Editorial Board

Executive Forum Editor DANIELLE GREENSTEIN

Outreach Chair

ASHLEY BLALOCK

\section{General Board}

REBECCA DIKTER

JAMES ELLISON

KELSEY GREENFIELD

PATRICK GRIFFIN

NATHAN HARVEY

ANDRES HERMIDA

MELISSA HUBBLE

WHITNEY JACOBS

BRITTANY JOHNSON

MELANIE LEHMANN

REBECCA MARINE

LAUREL MAROIS

SAMUEL MENAGED

COLIN MILAM

DAVID MITTEL

FRANK MOEHRLE
Executive Articles Editors ALEX CASTRO VAUGHN GLINTON

DANIELLE GREENSTEIN EDGAR SANCHEZ

Assistant Managing Editor CAROLE BECKER

\author{
Staff Editor \\ VICTORIA A. REDD
}

\section{Senior Articles Editors JOEL BENN \\ ALEXANDRA GRAVES \\ PHOEBE JOSEPH \\ BROOKE SHAFRANEK}

Executive Acquisitions Editor JOLEEN EAST

\author{
JUDEEN MOLYNEAUX \\ TODD MURGO \\ KATARINA O'REILLY \\ JACKSON PELLINGRA \\ ANDREA PICCO \\ KACIE ROYCE \\ ANTHONY SABATINI \\ ALI SCHEIN \\ RAINA SHIPMAN \\ AUBREY SMITH \\ MICHAEL ST. ONGE \\ RYAN TINDALL
}

SHELLIE GAINER WASHINGTON

RACHEL WILLIAMS

ALEXA WOODS 


\title{
ARTICLES
}

\section{"NO SHOTS, NO SCHOOL, NO KIDDING": THE LEGAL PROFESSION NEEDS A VACCINE TO ENSURE PROFESSIONALISM}

\author{
Debra Moss Curtis*
}

I. INTRODUCTION

II. The Public Health Crisis of Professionalism

III. Teaching and Modeling Professionalism in LaW SCHOOL AS A VACCINE.

A. Professionalism in Legal Education ...................................... 10

B. Professional Identity and Professionalism Education............ 12

C. Using Learning Outcomes as Tools to Demonstrate Professionalism Commitment

D. Full Time Faculty-Adjunct Partnerships/Professionalism Modeling by Faculty

E. Bar Associations Partnerships................................................ 22

F. A Professionalism Curriculum .................................................. 23

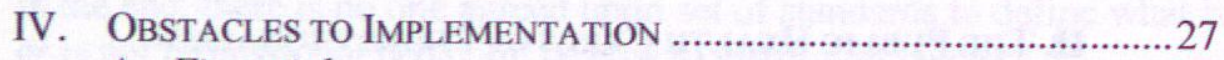

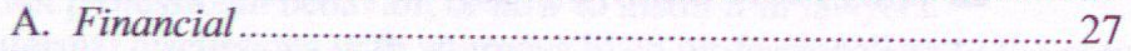

B. Regulatory-ABA Accreditation and Admission to the Bar ................................................................. 28

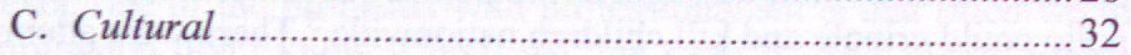

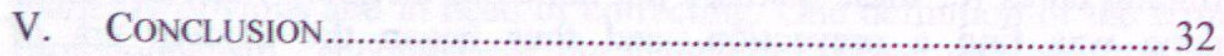

\section{INTRODUCTION}

In many states across the country, the month of August is filled with a severe no-nonsense message to parents of children enrolled or hoping to enroll in public school: "no shots, no school, no kidding."

* Associate Dean for Academic Affairs and Professor of Law, Shepard Broad College of Law, Nova Southeastern University.

1. See, e.g., Earl Rudder Middle School, No Shots, No School, No Kidding, FACEBOOK (Aug. 8, 2013), https://www.facebook.com/EarlRudderMiddleSchool/posts/228076027341607. 
health crisis that led to the requirement of mandatory vaccinations for school age children was so severe as to require this blanket mandate. ${ }^{2}$ Much like the spread of measles or mumps, the legal profession is experiencing its own public health crisis - a disease running through it that threatens to destroy it. That disease-a rampant lack of professionalism by attorneys, is tainting our justice system and harming the public in a widespread manner.

In the early days of disease epidemics, the strategy for containment was quarantine and attempting to cure, which ultimately led to the only true fix, vaccinations. ${ }^{3}$ Similarly, the legal system has responded to its own public health crisis by trying to cutoff attorneys from the general population and treat them, rather than working properly to prevent problems. This article argues that the legal profession has focused its efforts too much on trying to "cure" the professionalism problem through discipline, sanctions, and education of lawyers that have already shown signs of the disease instead of extensively using preventative education for newly forming lawyers to help prevent it.

Part II of this work discusses the professionalism crisis. Part III discusses ways that the legal academy is tackling this disease, and proposals to more effectively prevent it through a "vaccination" given while new lawyers are at their most formative stages. Part IV discusses obstacles to these plans, and Part V draws some conclusions from this analysis.

\section{The Public Health Crisis of Professionalism}

Before vaccinations became widely available, a variety of diseases caused a health crisis throughout the population. ${ }^{4}$ Measles, mumps, and polio could cripple and kill children nationwide. ${ }^{5}$ There were attempts at finding cures for these diseases but none did the job. ${ }^{6}$ What had to be done was find a prevention - and thus began the modern era of vaccinations.

Looking back a hundred years or so in the United States, the infant mortality rate and the rate of children dying before age five were each in the twenty percent range. ${ }^{7}$ In this time, before vaccines were available,

2. Alexandra Minna Stern \& Howard Markel, The History of Vaccines and Immunization: Familiar Patterns, New Challenges, 24 HEALTH AFF. 611, 611-12 (2005).

3. Michael Willrich, How the 'Pox' Epidemic Changed Vaccination Rules, NPR HEALTH changed-vaccination-rules.

4. Stern \& Markel, supra note 2.

5. Id.

6. Willrich, supra note 3.

7. Stern \& Markel, supra note 2. 
diseases such as measles, diphtheria and smallpox were among the biggest killers. ${ }^{8}$ Public health professionals cite the advent of immunizations for these diseases as one of the greatest achievements of the 20th century, representing what is considered the "greatest promise of biomedicine: disease prevention." At times, the crisis was so great, people's civil liberties were even infringed - near the turn of the 20th century, people were being inoculated by force, involuntarily. ${ }^{10}$

One of the reasons why prevention of disease is so important is that a cure, or a variety of cures for these various ailments were simply not effective. In contrast, vaccines for many diseases have proved so successful, that they are often taken for granted, and their challenges in having been formulated overlooked. ${ }^{11}$ These challenges included financial obstacles, regulatory barriers, and challenges to distribution ${ }^{12}$ as well as a wide variety of obstacles in the form of negative cultural responses or rejection due to widespread misinformation about them. ${ }^{13}$

Likewise, the legal profession has been trying ineffectively to "cure" the professionalism problem for many years. A variety of cures have been tried and tried again - attorney discipline, continuing legal education, and other behavior guidance after attorneys have displayed professionalism problems. From punishment to lectures - they simply are not working.

One key problem in solving the professionalism crisis is the endless debate on exactly what attorney "professionalism" means. ${ }^{14}$ Professionalism has been touted and dissected by the ABA, individual state Bars, the Carnegie Report, and hundreds of scholarly articles - but in the end, there is no one agreed upon set of standards to define what is or is not professional behavior, or how to instill it in lawyers. ${ }^{15}$

Informal discussions with attorneys liken professionalism to the now famous definition of obscenity, "You know it when you see it." 16 However, one of the problems with professionalism is that often we in the profession don't know it until we don't see it - and then it seems glaringly obvious and in need of correcting. One definition of the term professionalism "encompasses the standards, values and qualities of

8. Id. See also Amanda Naprawa, Medical Advice and Vaccinating: What Liability, $26 \mathrm{U}$.

FLA. J.L. \& PUB. POL'Y 265, 268 (2015).

9. Id.

10. Willrich, supra note 3 .

11. Stern \& Markel, supra note 2.

12. Id. at 615-17.

13. Global Vaccine Safety: Six Common Misconceptions About Immunization, World Health Organization, http://www.who.int/vaccine_safety/initiative/detection/immunization_mis conceptions/en/ (last visited June 8, 2016).

14. Paula Schaefer, A Primer on Professionalism for Doctrinal Professors, 81 TENN. L. REV. 277, 279-81 (2014).

15. Id. at $281-82$.

16. Jacobellis v. Ohio, 378 U.S. 184, 197 (1964). 
members of a profession." 17 Another defines professionalism as "the skill, good judgment, and polite behavior that is expected from a person who is trained to do a job well."18

Looking at this definition, it seems that the approach of punishing someone for not having a certain skill, good judgment, or for being welltrained in aspects of their profession is a foolish proposition. Instead, what we need to focus on is prevention of the unprofessionalism disease - through promulgating the skills and judgment by training and teaching these concepts in the formative stages, rather than trying to cut them out after they exhibit themselves badly. In other words, we need a vaccine against the bad cells of unprofessional behavior growing.

This is not the first work to compare professionalism problems to a health crisis for lawyers. ${ }^{19}$ Previously, the professionalism crisis had been discussed extensively by John T. Berry, the former Executive Director of the Michigan Bar and current Director of the Legal Division of the Florida Bar. ${ }^{20}$ In his feature article, Berry discussed that while some consider "manifestations of unprofessional conduct" a disease impacting the health of the legal profession, they were really symptoms of such a disease, which needed larger preventative health care measures. ${ }^{21} \mathrm{He}$ noted that unprofessional conduct, a symptom, can be treated with "medicine"-including practical education or anger management, but those were not ultimately cures for the underlying disease. ${ }^{22}$

Additionally, Berry discussed that while committees, commissions and task forces have helped shaped professionalism codes, and regulate the profession, the fact that professionalism is in worse shape than ever means a change in "diagnostics and health care plan" is needed. ${ }^{23} \mathrm{His}$ list of the "symptoms" of the "disease"- which certainly sounds familiar to anyone steeped in the issue of professionalism, includes incivility, discourteous conduct, inconsideration, anger issues, overcontentiousness, argumentativeness, willingness to distort manipulate and conceal to win, arrogance, condescendence, and abusiveness. ${ }^{24}$ Stemming from that, he concluded, the disease itself is really lawyers who have a lack of "healthy heart" (life philosophy or faith), misunderstanding of profession or fellow lawyers' expectations, lack of character/lack of integrity, drug, alcohol or other addictive behaviors,

17. Schaefer, supra note 14 , at 280.

18. Professionalism, MERRIAM-WEBSTER DiCTIONARY, https://www.merriam-webster. com/dictionary/professionalism (last visited July 22, 2015). (2006).

19. John Berry, A Check-Up on the Health of the Legal Profession, 17 Prof. LAw. 2

20. Id. at $9-11$.
21. Id. at 2 .
$22 . \quad I d$.
23. Id.
24. Id. at 9.


lack of law office management techniques, or lack of stress coping methods. ${ }^{25}$ Education in the formative years can help many if not all of these problems to be prevented, but to try to cure them after developing is simply not working.

However, there is no question that the profession currently is demonstrating an eagerness to "treat" these symptoms. Lawyers receive a constant barrage of invitations to CLE programs or other information directed to them that discuss "civility" or other professionalism issues. In May 2016, the Broward Bar Association was heavily promoting another such offering - "Got Civility?" a seminar to promote civility in the legal profession. $^{26}$ This offering had an interesting array of panelists and sponsors, including judges, attorneys, and the Florida Bar President-Elect speaking at or sponsoring the one-hour seminar and networking reception. $^{27}$ This seminar, and those like it, are excellent ways for a community of lawyers to gather and keep the issue of professionalism at the forefront, but they are not going to cure the problem. Rather, these types of programs would be excellent "booster shots" for a profession that has already been immunized, but cannot do the work of correcting a profession lacking fundamental formative education. There are two reasons for the potential failure of efforts like this. One, the real work in protecting the profession must happen from the beginning of a professional's career, becoming part of that lawyer's professional identity at the start, rather than retrofitting it later. Second, there is a danger in the belief that these types of programs are enough since such a belief could possibly prevent important strides that will really work to eradicate the disease. These types of attempted cures can be, as Berry noted, external fixes likened to "small Band-Aid on a huge gash." 28

The larger problem is that many states, instead of improving the health of the profession, are treating the disease of unprofessionalism with the hammer of the discipline system after the disease has manifested itself. Like radiation or chemotherapy, this "cure" to the disease is a caustic treatment that does more to eliminate individual diseased elements than to actually heal the profession or any individuals within it. In the past few years, the Florida Supreme Court has taken this "hammer approach" seriously by insisting "it wants the trend of escalating incivility among lawyers to stop." 29 In The Florida Bar v. Norkin, the Court suspended and

\section{Id.}

26. Broward County Bar Association, http://www.browardbar.org/events/\#! event/2016/5/ 24/cle-got-civility (last visited June 9, 2016).

27. Id.

28. Berry, supra note 19 , at 8 .

29. Samson Habte, Lawyer's 'Appalling 'Incivility Warrants Tougher Sanction than What Bar Sought, ABA/BNA Law. MAnual ON Prof. CONDuct (Nov, 20, 2013), https:/www.bna. com/lawyers-appalling-incivility-n17179880238/. 
publicly reprimanded an attorney for his behavior, including his unprofessionalism, and made an example of it. ${ }^{30} \mathrm{~A}$ complaint was filed against attorney Jeffrey Norkin, alleging misconduct for behaving "in an unprofessional and antagonistic manner during the course of litigating a civil case." 31 The referee recommended a ninety day suspension for various ethical violations in which aggravating and rehabilitating factors were found. ${ }^{32}$ Both the attorney and the Florida Bar appealed, the attorney sought only a public reprimand, and the Bar sought a one-year suspension with a public reprimand. ${ }^{33}$ However, the Supreme Court, noting it wished for this to be a case to be studied for its unprofessional behavior, imposed a two-year suspension and a public reprimand. ${ }^{34}$ This case garnered enormous attention since it is seen as blurring the lines between poor professional behavior, which usually considered aspirational, and the violation of attorney ethical rules, which traditionally carries penalties.

The Florida Bar has moved to stating that "all lawyers are expected to practice with professionalism[,]" and professionalism not merely aspirational. ${ }^{35}$ In addition to the traditional discipline system, the Florida Bar has proliferated professionalism panels to resolve professional complaints outside of the traditional discipline system, but in a formalized way. ${ }^{36}$ While circuit committees on professionalism have been in existence since 1998, these reimagined panels now known as Local Professionalism Panels, are defined as each being "[A]n entity independent of the Florida Bar which is established at the local level for the purpose of resolving complaints of alleged unprofessional conduct by attorneys practicing in that circuit." 37 The operation of these panels are detailed in orders through each circuit, and membership and procedures are in the discretion of the Chief Judge in each circuit and vary across the state. ${ }^{38}$ In short, however, these panels are voluntary for attorneys to appear, and they operate as a hybrid between quasi-discipline and

30. Fla. Bar v. Norkin, 132 So.3d 77, 93 (Fla. 2013).

32. Id at 79 .

33. Id. at 79 .

34. Id. at 93 n.5.

35. The Henry Latimer Center for Professionalism, CLE Professionalism Guidelines, FLA. B. (Nov. 18, 2015), http://www.floridabar.org/tfb/TFBProfess.nsf/840090c16eedaf0085256b61 000928dc/72e302f839a78f9d85256b2f006ccdc1?OpenDocument.

36. Gary Blankenship, Court Empowers Panels to Address Unprofessionalism, FLA. B. NEws (July 1, 2013), http://www.floridabar.org/DIVCOM/JN/jnnews01.nsf/cb53c80c8fabd49d $85256 \mathrm{~b} 5900678 \mathrm{f6c} / 8900945 \mathrm{~b} 7 \mathrm{c} 05$ ead $485257 \mathrm{~b} 90006 \mathrm{~b} 1215$ ! OpenDocument\&Highlight $=0$, profe
ssionalism, panel*

37. In Re: Code for Resolving Professionalism Complaints, 116 So.3d 280, 281-87 (Fla. 2013), http://www.floridasupreme court.org/decisions/2013/sc13-688.pdf.
38. Id. at 282 . 
educating attorneys after-the-fact of a problem arising. ${ }^{39}$ Once again, the profession has another attempt to cure a disease that needs preventative treatment.

Of course, Florida is not the only state to struggle with professionalism problems and how to treat such problems systematically. Many states have enacted creeds, oaths, rules, and aspirational goals to curb unprofessionalism. Some state bars take the position that professionalism rules are separate from the codes of professional conduct and mark a firm line between the aspirational and the enforceable legislation; however other states mandate professionalism rules that are encompassed into their conduct rules. ${ }^{40}$ It is clear that the attempt to cure the disease is nationwide and widespread.

In conclusion, however, none of these "cures" work. The legal profession instead needs to be inoculated against unprofessional behavior. The answer is education and modeling before lawyers are lawyers, with boosters of education throughout a professional life. Barriers to enacting this type of preventive medicine are similar to those in medical vaccines-finances, regulatory limitations, and cultural objections by many in legal education. But just as those public health obstacles were overcome, so must these, for the health of our profession.

\section{Teaching and Modeling Professionalism in Law SCHOOL AS A VACCINE}

It has been asserted that one of the causes of poor behavior in lawyers is that lawyers internalize their stress to survive, and they have been encouraged to be dehumanized. ${ }^{41}$ Historically, these tenets have been part of the law school curriculum for years. Thus, law school can accomplish the opposite of teaching professionalism as a behavior and instead create an environment of nonprofessional behavior where students do not consider themselves as part of a profession holistically.

One example of the wrong kind of training of future lawyers has been attributed to a typical torts class "where ethos and pathos is not considered except to say that you have no duty to save a drowning person." 42 While the legal standard of care in such a situation is likely to be discussed in a classroom, the moral aspects of such a situation are often ignored, such that "students begin to think that being human does not

39. See Blankenship, supra note 36 .

40. Id.

41. Gary Bauer, Addressing the Needs of Solo/Small Firm Practitioners Through Law School Based Programs to Reduce Stress in Practice Several Approaches, 6. T.M. CoOl.Ey J.
Prac. \& Clinical L. 1, 2-3 (2003).

42. Id. at 3 . 
have relevance to their professional status." ${ }^{43}$ As a result, tools to become a professional are not just absent from the curriculum, they are purposefully left out of the equation, which sends the message that they do not belong there. ${ }^{44}$ This historic trend needs to be reversed, with the affirmative incorporation of professionalism skills and judgment taught implicitly and explicitly.

There will always be critics who claim that you cannot teach professionalism, or that those who are going to behave badly will do so despite an extensive education. This latter tenet may be true, but we must think of future lawyers as falling somewhere on a continuum of professionalism. On one extreme, there will be some that have the skills, traits, and judgment to act professionally with no formal education at all in law schooi. They have either been trained before law school to have these skills, or perhaps these traits just naturally occur in some people. On the other end of the spectrum, there will be people who behave badly no matter what. No amount of education, information, or programs can prevent their choices from being unprofessional. These people are probably more likely to engage in behaviors that violate ethical codes of regulations for attorneys and end up in the attorney-discipline process, where there is a system that will catch their actions and respond. But most people likely fall in the middle of that spectrum as good people who have bad days or tendencies to behave in ways that are unprofessional, although it is not necessarily systematic. This vast majority of people are the group for whom "vaccinating" with professionalism education can make a difference in their careers. This tact could operate like the control of an epidemic disease in which some people never contract diseases despite no vaccinations and vaccinations fail for some, but for the vast majority, vaccinations prevent an undesirable result. Just as the struggle with germs is endless, so will be the struggle with professionalism in the attorney field. ${ }^{45}$ Legal education, by helping this majority, can improve the public health of the profession overall, if steps are taken early enough.

Like the current controversy regarding vaccines, the idea of including professionalism as part of a law school curriculum will have its detractors. It will include those who believe that like vaccines, this kind of education will do harm. They believe that this kind of learning of "soft skills" will replace "real learning" and turn out lawyers that are simply
not qualified to practice law.

Without fail, this kind of thinking is harmful to the profession. Legal education has recently been focused far too much on legal doctrine, rather
than producing self-sufficient thinkers and learners that can problem

43. Id.

44. See id.

45. Stern \& Markel, supra note 2. 
solve using a variety of methods. One reason for this misdirection of efforts has been the increased pressure of the bar exam on the curriculum of legal education. For example, the Florida Bar exam in recent years increased the already voluminous number of subjects tested on its statespecific exam. Necessary changes to this connection between legal education and licensing are a major obstacle to progress. It is a mistake to believe that courses in professionalism in time management, stress management, public speaking, or practical financial literacy, all of which can contribute to a well-rounded attorney who can manage all aspects of his or her job, would do harm and be less fruitful for the profession than preparing for a more traditional legal doctrine tested in a two-day exam.

It also has been argued that there is already evidence of a changing culture in law school since there are many committees now being formed to promote civility in the legal profession. ${ }^{46}$ The argument is that because practicing lawyers are now trying to promote civility in record numbers, the change already has happened. This is clearly not true. We are not witnessing the beginning of the turning tide on professionalism, but instead merely more widespread attempts at imposing a cure on an already-infected profession. It is a positive step that many attorneys now see the problem, but it is not enough.

What needs to happen instead is for teachers of new lawyersteachers of all sorts, not just traditional law school faculty - to frame the practice of law to include professionalism as a component with realistic expectations of professional growth. ${ }^{47}$ Expectations can be inculcated by all kinds of attorneys working together, and new lawyers seeing professional behavior modeled. ${ }^{48}$ Students can be made to understand the tenets of professionalism. They can be encouraged to take leadership roles, be directed to resources to answer questions, and ultimately empowered to manage their lives as attorneys, thus preventing widespread unprofessionalism outbursts. ${ }^{49}$

Law schools need to stop thinking about the universe of ethics and professionalism as being satisfied by a course, or multiple courses in professional responsibility. They need to understand the difference between the two universes and recognize the importance of each. Expansive thinking about a professionalism curriculum is a necessary contribution to the prevention of professionalism problems. Looking at the "disease" as laid out by John Berry in his healthcare checkup, ${ }^{50}$ many of the symptoms attorneys exhibit are problems that can be addressed with a wider variety of educational experiences. Looking specifically at

\footnotetext{
46. See Bauer, supra note 41 .

47. Id. at 41 .

48. Id. at 14

49. Id.

50. Berry, supra note 19 , at 8.
} 
the law school curriculum, the question then becomes if a law school were to make professionalism part of its curriculum, what could such a program look like? Various options are explored here.

\section{A. Professionalism in Legal Education}

Some schools are already picking up the professionalism banner in a variety of ways. In Florida, many schools introduce the concept of professionalism at orientation, including an oath of professionalism for students. ${ }^{51}$ In recent years, reports of law school activity to the Professionalism Center have also included professionalism enhancement programs, professionalism sessions incorporated into various classes, workshops on professionalism, professionalism oaths, professionalism days, lunchtime professionalism seminars, and awards. ${ }^{52}$

Nationwide, some schools have centers for professionalism, such as Thomas Cooley School of Law who indicates their mission as, "Supporting the law school's mission of preparing law students for professional practice, the Center for Ethics, Service, and Professionalism models and teaches ethics and professionalism, fosters and encourages service, and promotes commitment to our communities." 53

Other resources are trying to guide students in professionalism issues. One article serves to provide a framework of thirty questions for students to ask themselves at the start of their legal education careers. ${ }^{54}$ Such framework has the purpose to help schools develop a curriculum "to help each student's step-by-step development toward professional-formation learning outcomes beyond mere compliance with the law of lawyering." 55 The focus of such questions is to highlight both "proactive professional development toward excellence at all the competencies needed to serve clients and the legal system well" and "an internalized deep responsibility to clients and the legal system." 56

It is clear that law schools have started to make professionalism a topic of focus, but that more could be done to focus not just on rules and regulations of academic codes, but on fostering life-long positive

51. Henry Latimer CTR. For Professionalism, 2014-2015 Law School Reports on Professionalism (June 1, 2016), https://www.floridabar.org/tfb/TFBProfess.nsf/93534de21ecc6a $7285257002004837 \mathrm{a} 3 / \mathrm{b} 325 \mathrm{f} 29 \mathrm{e} 5521 \mathrm{fcf} 385256 \mathrm{db} 1004 \mathrm{ecbc} 8$ ! OpenDocument.

52. Id.

53. Ethics, Service, and Professionalism, W. Mich. U. T. M. COOLEY L. SCH., http://www. cooley.edu/ethics/ (last visited June 21, 2016).

54. Neil W. Hamilton \& Jerome M. Organ, Thirty Reflection Questions to Help Each Student Find Meaningful Employment and Develop an Integrated Professional Identity (Professional Formation), TENN. L. REV. (forthcoming May 13, 2016), http://papers.ssrn.com/
sol3/papers.cfm?abstract id=2779741.

55. Id.

56. Id. 
attitudes toward the profession. One such group already doing so is the National Institute for Teaching Ethics and Professionalism. ${ }^{57}$ This group, known as NIFTEP, was established in 2005, and operates as a consortium of six nationally recognized centers on ethics and professionalism, including the Louis Stein Center for Law \& Ethics at Fordham University, the Center for Legal Ethics and Professionalism at Mercer University School of Law, the Nelson Mullins Riley \& Scarborough Center on Professionalism at the University of South Carolina, the W. Lee Burge Endowment for Law \& Ethics at Georgia State Law, the Holloran Center for Ethical Leadership in the Professions at the University of St. Thomas School of Law, and the Center on the Global Legal Profession at the Maurer School of Law at Indiana UniversityBloomington. ${ }^{58}$ Such resources to enhance the teaching and experience of professionalism include biannual workshop on "innovative ways to teach legal ethics and promote professionalism" for both academics and practitioners and a "user-driven online community and resource library for ethics teachers, scholars and practitioners worldwide." 59

Other types of schools have taken an entirely different approach to incorporating professionalism into the curriculum. One medical school subjects students directly to an evaluation of professionalism skills in addition to their more traditional assessments. ${ }^{60}$ Law schools should be looking to how other professional schools accomplish this task, and the success of it, and follow suit.

While Professional Responsibility courses have been a staple of the legal education curriculum thanks to the Watergate scandal in the early $1970 \mathrm{~s},{ }^{61}$ it is clear there is a difference between ethical rules - as is generally taught in most professional responsibility classes, and professionalism as a manner of existing within the legal profession. Although ethics rules are broadly taught, many professional responsibility courses in law school are taught geared to a test- the Multistate Professional Responsibility Exam (MPRE), administered by the National Conference of Board of Bar examiners twice yearly, and required by the vast majority of state bars to be admitted. ${ }^{62}$ This courseand the test, are focused on the ABA Model Rules of Professional

57. National Institute for Teaching Ethics and Professionalism, Ga. St. U. C.L., http://law.gsu.edu/centers/national-institute-for-teaching-ethics-and-professionalism/ (last visited June 2, 2016).

58. Id.

59. Id.

60. Denise Platfoot Lacey, Embedding Professionalism into Legal Education, 18 J.L. BuS. \& ETHICs 41, 48 (2012).

61. Mark Curidden, The Lawyers of Watergate: How a '3rd Rate Burglary' Provoked New Standards for Lawyer Ethics, A.B.A. J., June 1, 2012. 2016).

62. The MPRE, NAT'L CONF. B. EXAMINERS, http://www.ncbex.org/ (last visited June 2, 
Conduct. ${ }^{63}$ These rules are divided into 8 chapters, and cover extremely important behavior for lawyers, including client-lawyers relationships, information about legal services, and transactions with other persons than clients, among others. ${ }^{64}$ But it is clear that a single course in Professional Responsibility rules does not meet a schools obligation to set lawyers on the right path for the profession in all necessary aspects. ${ }^{65}$

Another course that has been worked into law school curricula in a more widespread way that does benefit professionalism is law office management. ${ }^{66}$ Courses in law office management often include practical training in areas that can cause lawyers both ethical and professionalism issues - trust accounting, malpractice, client recruitment and retention, as well as increasing students' level of qualitative literacy as to reduce problems in their general areas of practice ${ }^{67}$ However, these courses are not directly professionalism education, but rather incidental professional education. They are excellent components of a much-needed larger plan.

\section{B. Professional Identity and Professionalism Education}

So what exactly is missing from law school? Law schools have failed to cultivate what can be considered two important aspects of lawyers' professional behavior-professional identity and practical judgment. ${ }^{68}$ Professional identity is a term that "encompasses a person's self-concept, values, and philosophy of lawyering" 69 Professional identity, at its core, is an important value of professional behavior by an attorney. If you know who you are, what your values are, and how you fit into your profession, there is no cause, need, or reason for unprofessional behavior, which often happens when lawyers are overstressed without a way to manage
their professional challenges.

The concept of "professional identity" seeks many of the same goals of the professionalism movement without being the same, and operates as an important part of that movement. ${ }^{70}$ While professionalism focuses

63. Id.

64. Model Rules of Professional Conduct: Table of Contents, A.B.A., $\mathrm{http} / /$ www.americanbar.org/groups/professional_responsibility/publications/model_rules_of.pr June 2, 2016).

65. Benjamin V. Madison \& Larry O. Natt Gantt, Symposium: Methods of Teaching and Forming Professional Identity: The Emperor has No Clothes but Does Anyone Really Care? How Law Schools are Failing to Develop Students' Professional Identity and Practical Judgment, 27
REgENT U. L. REv. 339, 341 (2014-2015).

66. Richard S. Granat \& Stephanie Kimbro, The Teaching of Law Practice Management

and Technology in Law Schools: A New Paradigm, 88 CHICAGO-KENT L. REV. 757 (2013).

68. Madison \& Gantt, supra note 65 , at 341.

69. Id.

70. Id. at 343 . 
on external conduct or behavior, professional identity and practical judgment issues are related to internal beliefs and standards. ${ }^{71}$ If you can teach the importance of internal standards, you can affect a lawyer's external behavior. If professional identity "challenges lawyers to internalize principles and values such that their professional conduct flows naturally from their individual moral compass" and lawyer professionalism is "adherence to standards or norms of conduct beyond those required by the ethical rules"72 then it is clear to see how professional identity education is a necessary part of the professionalism crisis vaccination.

The goal that lawyers act "professionally as part of who they are and as a result of their integrity" is a key part of professional identity formation. ${ }^{73}$ The following principles have been cited as guides in forming professional identity and practical wisdom in legal education:

1. Know the proper aim or purpose of both being a lawyer and this particular representation;

2. Know how to improvise, which requires "balancing conflicting aims and interpreting rules and principles in light of particularities" of the situation;

3. Know how to read context and see the particularities in a situation;

4. Know how to take the perspective of another, including developing empathy for others;

5. Know how to make emotion an ally of reason; and

6. Know how to make use of their accumulated experiences as a person and a lawyer. ${ }^{74}$

These excellently articulated principles should also be part of a working definition of professionalism, and it is clear that these concepts can and should be taught in legal education.

It has been noted that law students who do not develop a "sense of their internal values and honor those as part of their judgment in practice are far more likely to lose their sense of self." 75 This concern speaks directly to that group of attorneys falling on that professionalism continuum-those who can be educated and influenced. An attorney who loses their sense of values can begin acting - in the name of winning a case, client needs, money, or desperation - in ways that do not explicitly fall through the floor of ethical violations, but below the standard of

71. Id.

72. Id. at $344-45$ (emphasis added).

73. Id. at 346.

74. Daisy Hurst Floyd, Practical Wisdom: Reimagining Legal Education, 10 U. ST, Thomas L.J. 195, 205-06 (2012).

75. Madison \& Gantt, supra note 65 , at 348 
professionalism that is necessary to the profession. But a law student whose substantive and procedural legal education is embedded with professional identity education, thus learning judgment internally and the appropriate corresponding skills to use it will learn to view their behavioral choices in their work as integrated with whom they are and what they can and should stand for as humans - and will act accordingly in a professional manner. The disease will be prevented.

The authors of a recent article on professional identity conducted a study regarding the existence of professional identity formation in course offerings, by asking Associate Deans how many courses in the JD curriculum had learning outcomes for courses that included the develoyment of students' professional identity. ${ }^{76}$ Of the 60 schools that responded regarding required courses, 6 schools indicated no required courses did, while 28 schools indicated 1 to 3 courses did, 9 schools had 4 to 6 courses, five schools had 7 to 9 courses and 12 schools indicated 10 or more courses. ${ }^{77}$

The survey also examined whether one course in the required law school curriculum-Professional Responsibility-incorporated professional identity education. ${ }^{78}$ The results showed that one response indicated it was not addressed, 5 responses indicated it was addressed but not emphasized, 26 responses indicated that it was emphasized but not as much as the content of the rules, 11 responses indicated that it was treated equally to the rules, and one indicated it was emphasized more than the
rules.

This one required course is not enough. By contrast, the survey revealed that many schools indicated a higher emphasis in professional identity related skills in extracurricular or mentoring settings, rather than classroom ones. The results demonstrate a shift in progress in bringing professional identity to legal education, but that many schools, rather than either requiring the skills or embedding them throughout the curriculum to set a culture, still considered them "extra" skills for students to learn on their own initiative. We must move the thinking further to incorporating the teaching into required ways.

Professional education has established that there exists an "emotional maladjustment" when a lawyer has one set of values that they apply to their work and another to their life. ${ }^{80}$ The consistency between personal beliefs and behavior has been noted as a key factor in leading a "healthy professional life." 81 The concept of "self-loathing" has been applied to

76. Id. at 361 .

77. Id. at 362 .

78. Id. at 363.

79. Id.

80. Id. at 351 .

81. Id. at 353 . 
describe a lawyer who ignores internal conflicts in making decisions against their own ethical compass. ${ }^{82}$

This concept - bringing personal codes of behavior to work life-is the core of getting students to behave professionally - teaching them that there is really one set of values applied to all areas of life. Legal education has up until this point, utterly failed to adopt this attitude, instead establishing for new lawyers the idea that there are special ethical rules for lawyers that operate outside of the world of personal judgment instead of being integrated into it. Professional identity education can prevent this belief that contributes to unprofessional behavior.

At the heart of the professionalism movement's success is one tenet: we need to stop labeling unprofessional conduct as tolerable. ${ }^{83}$ To succeed in having a profession that acts appropriately, we must foster people from the beginning as lawyers in all aspects of that reality. We must include a curriculum of professionalism that includes professional identity education so that in the formative years of the profession, future lawyers know who they are and have a philosophy of life that enables them to act in accordance with it throughout their careers. ${ }^{84}$ The concepts of professional identity education have been discussed above, but it is clear that in recent years, there have been great strides in the awareness of professional identity education. ${ }^{85}$

The Florida Bar recently dedicated an entire issue of its magazine to "mindfulness" in an effort to change the culture of what is acceptable for lawyers to consider part of their professional education. ${ }^{86}$ This April 2016 issue was dedicated to educating lawyers about another part of their professional lives, not involving the substance of law, but instead about being tuned in to their lifestyle. ${ }^{87}$ Mindfulness is an important aspect of professionalism. According to some, a large body of empirical evidence suggests that much of lawyer misconduct happens "unconsciously and unintentionally, even when the attorney has basic knowledge of the relevant ethical rules." 88 Mindfulness includes a maintaining of a "moment-by-moment awareness of our thoughts." 89 By doing so, mindfulness can help with professionalism by helping someone focus on how they are behaving in any given set of circumstances. Following up

82. Id. at 349 .

83. Berry, supra note 19 , at 9.

84. See id. at 9-10.

85. See Madison \& Gantt, supra note 65 , at 360.

86. See Fla. B.J., Apr. 2016.

87. See id.

88. Peter H. Huang, How Improving Decision-Making and Mindfulness Can Improve Legal Ethics and Professionalism (Sept. 5, 2014), 21 J.L. Bus. \& ETHICs 35-76 (2015), available at https://ssrn.com/abstract=2474448.

89. Jon Kabat-Zinn, What is Mindfulness?, GrEATERGOOD.BERKELEY.EDU, http:/greater good.berkeley.edu/topic/mindfulness/definition. 
professionalism that is necessary to the profession. But a law student whose substantive and procedural legal education is embedded with professional identity education, thus learning judgment internally and the appropriate corresponding skills to use it will learn to view their behavioral choices in their work as integrated with whom they are and what they can and should stand for as humans - and will act accordingly in a professional manner. The disease will be prevented.

The authors of a recent article on professional identity conducted a study regarding the existence of professional identity formation in course offerings, by asking Associate Deans how many courses in the JD curriculum had learning outcomes for courses that included the develomment of students' professional identity. ${ }^{76}$ Of the 60 schools that responded regarding required courses, 6 schools indicated no required courses did, while 28 schools indicated 1 to 3 courses did, 9 schools had 4 to 6 courses, five schools had 7 to 9 courses and 12 schools indicated 10 or more courses. ${ }^{77}$

The survey also examined whether one course in the required law school curriculum-Professional Responsibility-incorporated professional identity education. ${ }^{78}$ The results showed that one response indicated it was not addressed, 5 responses indicated it was addressed but not emphasized, 26 responses indicated that it was emphasized but not as much as the content of the rules, 11 responses indicated that it was treated equally to the rules, and one indicated it was emphasized more than the
rules 79

This one required course is not enough. By contrast, the survey revealed that many schools indicated a higher emphasis in professional identity related skills in extracurricular or mentoring settings, rather than classroom ones. The results demonstrate a shift in progress in bringing professional identity to legal education, but that many schools, rather than either requiring the skills or embedding them throughout the curriculum to set a culture, still considered them "extra" skills for students to learn on their own initiative. We must move the thinking further to incorporating the teaching into required ways.

Professional education has established that there exists an "emotional maladjustment" when a lawyer has one set of values that they apply to their work and another to their life. ${ }^{80}$ The consistency between personal beliefs and behavior has been noted as a key factor in leading a "healthy professional life." 81 The concept of "self-loathing" has been applied to

\footnotetext{
76. Id. at 361 .

77. Id at 362 .

78. Id at 363 .

79. Id.

80. Id. at 351 .

81. Id. at 353 .
} 
profession. ${ }^{94}$

Part (c) of this standard bolsters the argument for including professionalism as a core tenet of legal education. By using this standard as a guideline, law schools can change the focus of legal education programs by incorporating a wider variety of learning outcomes as part of their institutional and classroom goals. Rather than doubling down on the traditional range of outcomes that legal education has promoted, such as legal doctrine and analysis, this new accreditation requirement is actually an opportunity for law schools to define their programs in wider ways.

In my own law school, we have adopted a new standardized set of learning outcomes that include outcomes for legal education far beyond traditional doctrine or skills. Although a work in progress, our list considers law students' education holistically, in an effort to have our curriculum incorporate a wide variety of skills for our students as they become professionals. Our faculty can choose any of these learning outcomes from this list for their individual course outcomes. Then, by institutionally examining the gaps and overlaps in what our faculty chooses as learning outcomes, we can determine where our curriculum needs to be enhanced, and ensure that all aspects of a student's necessary education are met. Our list includes:

1. Demonstrate a knowledge of substantive legal doctrine fundamental to this course (e.g., case law, legal concepts, legal principles, regulations and statutes).

2. Identify legal issues and apply legal reasoning and analysis to solve problems in a logical and structured manner to issues covered in this course.

3. Communicate orally or in writing, or both, the legal reasoning and analysis regarding issues covered in this course.

4. Research legal issues thoroughly and efficiently.

5 . Demonstrate a proficiency in reading critically the materials assigned for this course.

6. Understand the obligation to adhere to the values of the legal profession (e.g., (1) providing of competent representation, (2) striving to promote justice, fairness, and morality, (3) striving to improve the profession, and (4) engaging in professional self-development).

7. Demonstrate ethical and practical judgment and active

94. ABa Standards and Rules of Procedure for Approval of Law Schools, 20152016 A.B.A. SEC. Legal Educ. \& Admissions to B., standard 302, at 15, http://www.american bar.org/groups/legal_education/resources/standards.html. 
listening skills in communications (e.g. with clients, attorneys, and related parties).

8. Use technology to meet ethical duties of the legal profession (e.g. to address duties of confidentiality for all communications, to fulfill filing and other judicial obligations, and to keep abreast of technologies that affect accuracy of information provided to clients).

9. Anticipate, recognize and resolve obligations ethically.

10. Demonstrate self-directed learning practices for life-long learning.

11. Demonstrate commitment and engagement when providing legal services.

12. Demonstrate creativity and innovation when providing legal services.

13. Use stress management techniques.

14. Develop business development skills, (e.g. attracting clients, retaining clients, entrepreneurship, networking, mentoring, and business development skills).

15. Demonstrate effective client counseling when providing legal services.

16. Demonstrate effective negotiation strategies and styles appropriate for client representation.

17. Demonstrate cultural competency and cultural empathy.

18. Demonstrate effective team participation (e.g., collaboration, management, and support).

19. Demonstrate factual investigation, interviewing, and questioning skills.

21. Demonstrate the following pre-trial litigation skills: drafting of pleadings, discovery, and motion practice.

22. Demonstrate the following trial litigation skills: witness examination, strategic use of evidence, developing and delivery opening statements and closing arguments.

23. Demonstrate the following appellate litigation skills: understanding the appellate process, effective brief writing, and effective oral argument.

24. Demonstrate transactional planning and drafting skills (e.g., effective use of written communications to clients or third parties, completion of closing documents, and creation of contracts or other documents that effectively translate deal
terms or intent). 25. Demonstrate the skills, strategies and procedures used in
transactional practice (e.g. due diligence, risk management,
client counseling and problem solving through client counseling and problem solving through drafting). 
26. Demonstrate the skills, strategies and procedures used in mediation.

27. Demonstrate effective organization and management of legal work.

28. Demonstrate strategic planning skills.

29. Demonstrate effective process management skills (e.g. time management, project management, and organization of work product, including one's own work, the work of staff, and the work of colleagues).

30. Demonstrate quantitative literacy (e.g., accounting and finance reporting, statistical reporting, and competency to apply basic finance principles).

31. Demonstrate the ability to see the world through the eyes of others.

32. Demonstrate client relationship, management, and stewardship proficiency.

Our school is not the first, or alone, in seeing these outcomes representing necessary skills in legal education and aligning with the concept of professionalism. Other authors have been urging for a broadening of law school learning outcomes to encompass widening competencies for some time. For example, Shultz and Zedeck have established a set of skills associated with effective lawyers that is a great guiding tool for legal education. ${ }^{95}$ Such skills include character, working with others, and conflict resolution in a manner that enables those to see the world through the eyes of others. ${ }^{96}$

Law schools also will be required, in accordance with ABA Standards, to assess whether their learning outcomes are being met. ${ }^{97}$ Our list clearly draws on these ideas to accomplish the common goal of turning out professional attorneys, and as an institution, will be moving on to the next stage of determining how to assess these outcomes to measure their completion.

According to Neil Hamilton and Jerry Organ, as of December 2015, of the 33 ABA accredited law schools that posted learning outcomes on their website,

[E]ight have adopted essentially the minimum Standard 302(c) learning outcome that students will be competent in the "[e]xercise of proper professional and ethical responsibilities to clients and the

95. Marjorie Shultz \& Sheldon Zedeck, Predicting Lawyer Effectiveness: Broadening the Basis for Law School Admissions Decisions, 36 LAW \& SOC. INQUIRY 620 (2011).

96. Id. at 632 n.5, tbl.8.

97. ABA Standards AND RULES OF PROCEDURE FOR APPROVAl OF LAW SCHOOLs, supra note 94 , standards $314 \& 315$, at 23. 
legal system," while 25 have adopted a learning outcome that goes beyond the minimum of Standard 302(c) and further defines "professional and ethical responsibilities to clients and the legal system" to include "values that [students] are expected to understand and integrate into their professional lives." 98

One step could be to add a "doctrinal" course on professionalism, covering not rules of ethics, but the vast variety of behaviors encompassed in the multitude of definitions of professionalism - how to handle one's self in the profession in a way that gives students the skills and behaviors necessary to operate properly. Another tact is to add assignments to existing courses in which students can development their professional identity and judgment, such as blogging in relevant subjects. ${ }^{99}$ However, were there such a course focusing on professionalism, and even if it were required, confining this education to one two-to-four credit semester experience is nowhere near the structured level of exposure necessary to be trained well for a profession. For this larger plan, law schools need to do more than simply add a course to the curriculum.

Skills that lead to a high professionalism standard cannot be gained in a one-time education experience. Because professionalism involves an entire approach, an attitude to a lawyer's life, those messages must be threaded through the other daily skills of new lawyer training. These skills are just as critical to the survival of the legal profession as ensuring students have a foundational knowledge in law. In law, we know that substantive knowledge will change and thus a law school's goals should be to build a base knowledge to understand the scope of a subject matter, and to train future lawyers to find the most current versions of law, along with the analytical skills needed to absorb and use them. Law schools should be doing the same with professionalism training. In the future, lawyers will find themselves in situations that they cannot imagine or predict in law school-forks in the road as to how to behave that could not be conjured by even the most outrageous in-class hypothetical. Students must have that same basic knowledge and the skills and tools to use it to analyze and solve professionalism problems. These skills, gained through immersion, must be a foundation in understanding how professional behavior is aligned with their own beliefs, along with the tools to stay abreast of the changes in the profession and analyze them in any new situation that comes along. In this manner, education can truly vaccinate against problems.

98. Hamilton \& Organ, supra note 54, at 2.

99. See Jodi S. Balsam, Law Blogging Engages Students in Writing that Connects Theory to Practice and Develops Professional Identity, 23 PERsP.: TeACHING LEGAL RES. \& WriTING 145
(2015). 


\section{Full Time Faculty-Adjunct Partnerships/Professionalism Modeling by Faculty}

Law schools need to do more than add courses or coverage to a curriculum. Law schools need to rethink the professionalism message they send from their own faculty to students in the classroom in their teaching methods across the board. While law school classrooms are changing with modern faculty, the "traditional" view of how law school classes are conducted can do more harm than good in the professionalism education movement. It is no secret that many traditional podium professors, in the name of toughness, teaching the "value of studying" or for flat-out intimidation purposes, often display the opposite of professionalism in the classroom. But professional lawyers don't purposefully embarrass their unprepared opponents. Professional judges do not berate lawyers who are not successfully arguing for their clients. Professional lawyers know how to accomplish the goals of what they want and need for their clients without rudeness, attitude, superiority or belittling. There are many law professors however, who still take those tactics, and thus, who are in effect, modeling that poor behavior for their students for the future. It is a kind of oxymoron that professors insist that they are being tough because they are immersing students in the legal profession from the start of law school, yet behave in unprofessional ways that in fact contradict professional lawyering.

In addition to behaviors changing from within, law school must be enhanced with better connectivity in the classroom with practicing lawyers known for professional behavior in the community. These adjuncts, instead of only having their own specialty doctrinal classes, could be paired with full-time faculty to enhance more classroom experiences from a practice point of view, thus embedding professionalism lessons throughout the curriculum. When a student is unprepared, or in some way acts unprofessionally in the school environment, that adjunct could bring real world experience into the situation, explaining what would happen in practice, if for example, a student had not prepared the proper authority to back up their argument or answer questions from a judge. Redirecting the conversation to the real world consequences and drawing attention to the problem in that way, with the credibility of one experiencing it daily could bring about a change of behavior systematically in students far better than the yelling and the histrionics that unfortunately are the reality in many law classrooms. ${ }^{100}$

100. It is no secret that many traditional podium professors, in the name of toughness, teaching the "value of studying" or for flat-out intimidation purposes, often display the opposite of professionalism in the classroom. M.H. Sam Jacobson, The Curse of Tradition in the Law School Classroom: What Casebook Professors can Learn from Those Professors Who Teach 


\section{E. Bar Associations Partnerships}

The legal community as a whole must be an important partner in this preventative education vaccine for new lawyers. While it may not be possible to immerse every classroom experience with practical professionalism experiences, schools should also be trying to embed the law school experience as a whole with these lessons. Law student interaction with the legal community is simply too brief, sporadic and formal. The legal profession is a marathon of a career, not a sprint - and as such, the main interaction that many first year students receive - a brief inspirational "pump-up" speech at orientation by a visiting dignitary is simply not enough. We know that students will not master a substantive legal concept by exposure to it once, yet, we expect an inspirational speech at orientation or graduation to take care of aligning a student's professionalism compass properly.

One solution is to better utilize local bar associations. Bar Associations conduct a variety of activities including receptions, CLE seminars and meetings. Law schools have classrooms and reception spaces, along with hundreds of students who could benefit from being in some way a part of these events. This newly developed relationship could be symbiotic in increasing the professionalism of both students and attorneys. Bar Associations could have a readily available place properly set up for their needs - a classroom, for example, with proper technology and seating for a seminar, or a reasonably priced venue for an event. Law students can take part in these events in various ways. First, available seats at education programs could be distributed to law students in a variety of fashions - first come, or selected students who have achieved in certain areas, or students enrolled in a particular subject matter course, moot court team, or clinical or field placement opportunity. Second, students could assist with the running of such a project. Such volunteer work by students will help demonstrate - in a tangible way - that this type of service is part of being a professional in the community, while attorneys supervising these students grow professionally from this kind
of service.

Last, simply by having these programs at law schools will help students become exposed to the professional concept of service, and further education. They would see, on a regular and routine basis, attorneys furthering their learning, interacting in professionally socially ways that do not include a zero sum win/loss outcome for clients, and have the opportunity to practice new found professional skills within a service will be taught organically - the service equivalent to a live-client 
experience. Attorneys will be constantly reminded of their role in the community to educate and model professional behavior.

\section{F. A Professionalism Curriculum}

My own law school convened a committee some years ago to establish a professionalism program that pervaded the law school experience. What follows is much of our plan, ultimately not adopted into action in full, but much of which came to light enacted through other opportunities and programs for students created throughout the law school. These ideas, combined with further knowledge gained from professional identity education, could hopefully serve as a guide for other law schools seeking to enact a comprehensive professionalism curriculum, or to adopt individual aspects of a professionalism program or a way to introduce professionalism education into their law school experiences.

\section{Ad Hoc Professionalism Curriculum Committee Recommendations $^{101}$}

Summary of Proposed Curriculum

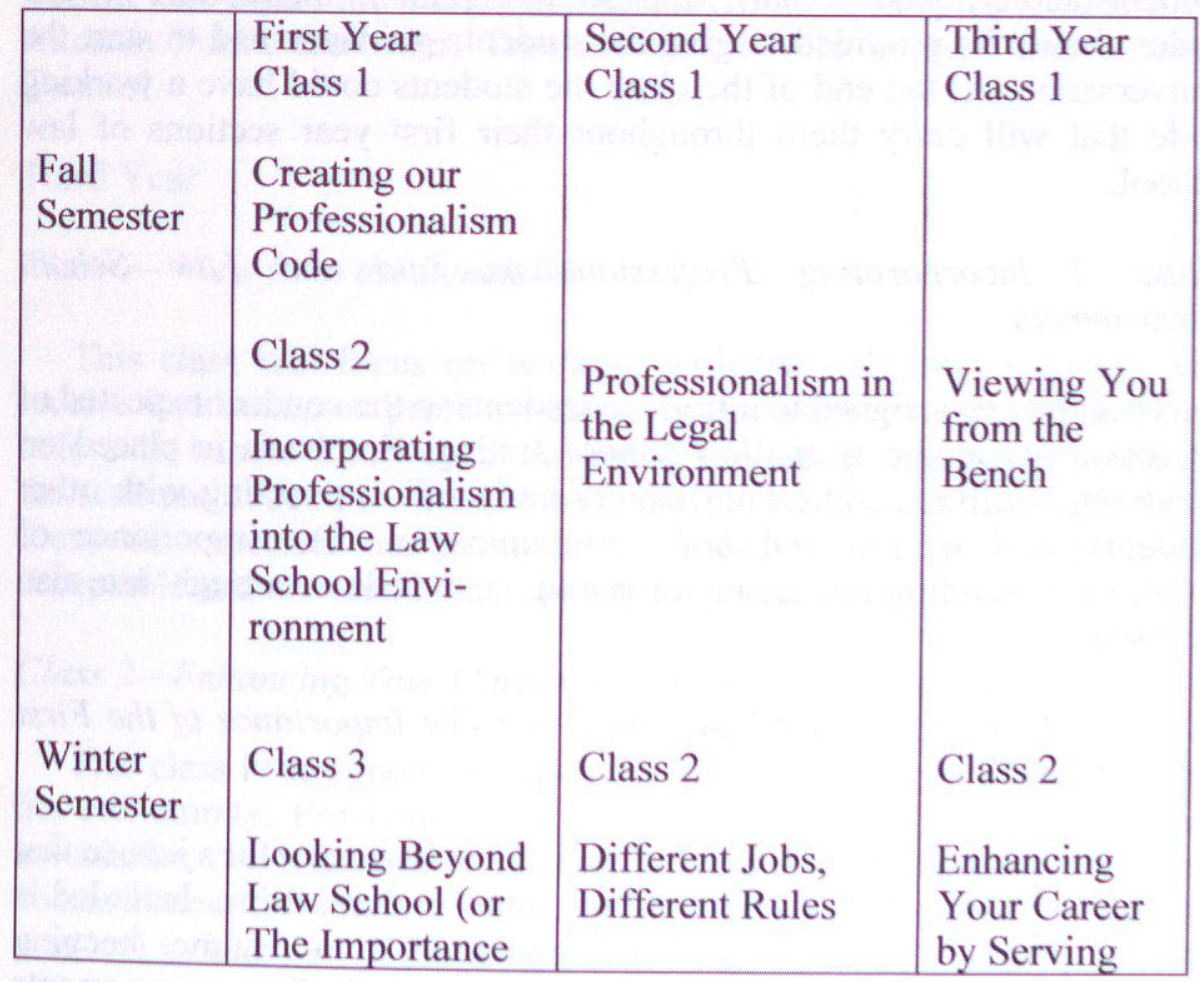

101. Professionalism Program Proposal (2010). 


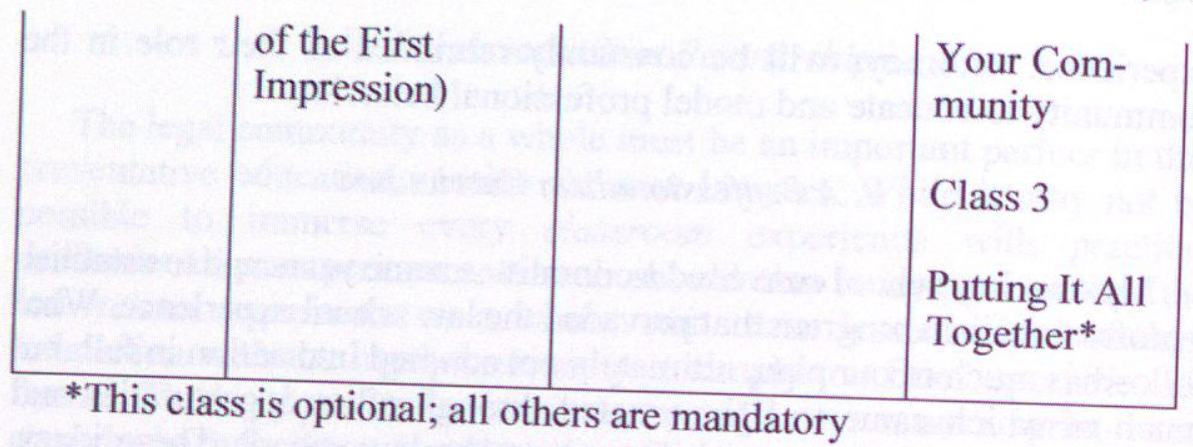

\section{Course Details and Descriptions}

First Year

\section{Class 1-Creating Your Professionalism Code}

This class is designed to allow students to discuss and develop a professionalism code for their section. Students are to discuss what the conduct of a professional should be in and out of the classroom for student-faculty, student-staff, and student-student interaction. Model codes should be provided to give the students guidance and to start the conversation. At the end of the class the students could have a working code that will carry them throughout their first year sections of law
school.

\section{Class 2-Incorporating Professionalism into the Law School
Environment}

This class is designed to introduce students to the conduct expected of professionals in the larger law school setting. Emphasis is placed on resolving conflicts, addressing faculty and staff, interacting with other students, and written and oral communication. The importance of fulfilling commitments, being prepared, and follow-through are also

Class 3-Looking Beyond Law School (or The Importance of the First
Impression)

This class is designed to prepare students to interview for a job, so that students will learn how to act professionally in that setting. Included is how to prepare for an interview, preparation of a resume, keeping appointments, being on time, behavior at out-of-office engagements
(social, networking, etc.), and other skills. 


\section{Second Year}

\section{Class 1-Professionalism in the Legal Environment}

This class focuses on the expectations of a student in a clinic or internship working environment. Expanding on Class 3 of the First Year Curriculum, this class provides further instruction to students on professionalism in the work environment. It will emphasize communication skills (oral and written); discuss the expectations for students, how to resolve conflicts or dilemmas that might arise, and how to leave a placement with a positive perception for both the student and the firm.

\section{Class 2-Different Jobs, Different Rules}

This class will consist of 3 or 4 panels - each with a different focus on professionalism concerns in specific fields. The student will have to attend one of the panels determined by his or her interest. The purpose of the panel is to have actual practitioners discuss what is expected from a student who enters the market in a specific field. Examples include State Attorney/Public Defender, Transactional, Public Interest, and General Counsel.

\section{Third Year}

\section{Class 1-View from the Bench}

This class will focus on working with the judiciary. Students will receive instruction on professionalism issues as they relate to practicing before the bench. All levels of the bench, including magistrates, and both the state and federal bench will be invited to participate. Instruction will focus on expected interaction with the bench and what behavior is acceptable and unacceptable as practicing members of the bar.

\section{Class 2-Enhancing Your Career by Serving Your Community}

This class is designed to emphasize the importance of giving back to the community. Pro bono work is discussed as well as service to bar association committees, local charities, and underrepresented communities. The importance of service to the practice of law and to the personal satisfaction of the lawyer will be discussed. 
This networking event is to be the capstone event for the Professionalism Curriculum. Invited guests and students will interact and have an opportunity to put into practice many of the skills taught during the 3-year course. It is anticipated that faculty, the judiciary, alumni, and the practicing community will be invited to participate. Those students who choose not to attend this function will be asked to attend a bar sponsored event instead.

Such a curriculum attempts to cover the many aspects encompassed in a definition of professionalism, and expose students to professionalism issues in as many situations, and from as many perspectives as possible. However, various concerns often cut off the enacting of such a program before it even can be conceived or launched. One problem schools may have to creating such a professionalism curriculum is determining who is ultimately in charge of its coordination and operation. Various options exist - a Dean of Experiential Learning, an Academic Support Program in existence, an Academic Dean, or a particular Faculty member named as an administrator for Professionalism could all accomplish and support a program properly.

A second concern is how a program, which should by necessity include practitioners, can recruit and reward participation by the legal community. This problem should have a short shelf life, as generations of law students educated under such a curriculum will hopefully be eager to give back to law schools to continue the education. In the short term, any programs involving practitioners should include the awarding of continuing legal education credits for those participating, as well as opportunities for those attorneys to use such a program to help grow their businesses. While pay likely should not be a component, these other benefits can easily be both incentive and reward. Third, scheduling concerns often take hold - how to fit such programs into a busy law school schedule, as well as concerns about providing equal opportunity to students in full time and part time schedules. Friday afternoons, often underutilized in legal education, are ideal times to bring together students and members of the profession - who may be able to contribute at that time better than a more prime mid-week time. Additionally, weekends, lunch hours and early evenings may also be available. However, scheduling may be the largest obstacle, due to external forces.

These Administrative concerns, which often loom large, should not deter law schools from including professionalism into their universe. The one fear - that an entire curriculum cannot be enacted or it cannot be scheduled perfectly or initially have huge participation - should not be a deterrent to getting started. Much like a diet for one's health, even small improvements, even if not perfect, will contribute to an improvement. 
The only minimum level at which professionalism education is useless is to have none at all.

\section{OBSTACLES TO IMPLEMENTATION}

These suggestions for incorporating professional identity and professionalism education into legal education share systematic obstacles to enacting them in legal education that have the potential to stand in the way of law schools moving forward with a professionalism education program. Three big obstacles are detailed here, along with suggestions on how to move past them.

\section{A. Financial}

Implementing preventative professionalism education for law students and lawyers comes at a financial cost. Law schools are not structured or generally inclined to finance changes to education of this sweeping nature, but it is possible. Financial costs may include a restructuring of staff to teach in these new areas. However, as law school enrollments shrink, fewer traditional doctrine teachers may be needed, and new faculty with these more expansive teaching portfolios may be hired, or existing faculty may be retrained. Either option comes at a cost. Bringing in adjunct faculty to partner and model behavior also could increase the payroll. Although traditionally adjuncts do not earn large amounts for teaching in legal education, pervading a curriculum with them could add up to a significant cost. Even partnering with the voluntary bars could come at a financial cost to law schools at a time when many law schools are shrinking, not expanding budgets.

Some of these endeavors could be turned into profit or self-financing ones, such as CLE seminars that can cover their costs and provide marketing exposure to law schools that would otherwise draw costs from elsewhere. Additionally, law schools can use the opportunity of senior faculty voluntarily retiring to replace them with those in different areas of expertise, who by generally being less experienced will, at least in the short run, lower the payroll. Additionally, professionalism programs may be supported by being sponsored by lawyers and law firms-who could additionally benefit from this partnership.

Universities need to be creative in this problem solving and patient in this restructuring of legal education. If the goal of a university is to ensure a long term survival of its college of law, this type of investment in realigning its curriculum is vital to ensure that the legal education that universities are providing is the best possible to prepare students to be professional members of the profession. 


\section{B. Regulatory-ABA Accreditation and Admission to the Bar}

Although there is plenty of room in legal education for innovation, there are still regulatory standards by the ABA Council of Legal Education that drive parts of the law school curriculum. ${ }^{102}$ Such standards include requiring certain kinds of courses, such as a first year legal writing experience and an upper level writing experience, in addition to a new requirement of six credits of experiential education for students. ${ }^{103}$ Additional restrictions exist for law school curriculum as to how many credits must be taken and when, whether those credits may be taken in distance education, and who may teach certain kinds of classes. ${ }^{104}$ In short, law schools are not free to do anything they wish in legal education, but there is plenty of room for innovation. One area, however, where there the leeway has narrowed is the regulation of the bar exam and the pressure it exerts on legal education.

According to ABA Standard 316, law schools must demonstrate a certain bar passage rate to be in compliance with the Rules. ${ }^{105}$ In part, the rule states:

\section{Standard 316. BAR PASSAGE}

(a) A law school's bar passage rate shall be sufficient, for purposes of Standard 301(a), if the school demonstrates that it meets any one of the following tests:

(1) That for students who graduated from the law school within the five most recently completed

calendar years:

(i) $75 \%$ or more of these graduates who sat for the bar passed a bar examination; or

(ii) in at least three of these calendar years, $75 \%$ of the students graduating in those years and sitting for the bar have passed a bar examination.

In demonstrating compliance under sections (1)(i) and (ii), the school must report bar passage results from as many jurisdictions

102. ABA Standards and Rules of PROCEDURE For APPROVAL OF LAW SCHOOLS, supra note 94 , standard 303 , at 16 .

103. Id.

104. Id. standard 311 , at $21-22$.

105. A new version of this standard has been proposed to clarify the existing deadline that 75 percent of students pass within two years. See Elizabeth Olson, A.B.A. to Enforce Stricter Timeline for Law Graduates to Pass the Bar Exam, N.Y TIMES, Mar. 14, 2016, http://www.nytimes.com/2016/03/15/business/dealbook/aba-to-enforce-stricter-timeline-for-la w-graduates-to-pass-the-bar-exam.html? $\mathrm{r}=0$. 
as necessary to account for at least $70 \%$ of its graduates each year, starting with the jurisdiction in which the highest number of graduates took the bar exam and proceeding in descending order of frequency.

(2) That in three or more of the five most recently completed calendar years, the school's annual first-time bar passage rate in the jurisdictions reported by the school is no more than 15 points below the average first-time bar passage rates for graduates of ABA-approved law schools taking the bar examination in these same jurisdictions.

While law schools certainly have other motivations besides ABA Standards for wanting their students to pass the bar exam, the recent attention on the school's passage rates, combined in some states with an increase in the minimum passing score for a bar exam, an increase in the number of subjects tested on some bars and a decrease nationwide in the average scores, has pushed schools - whether by choice, student demand, or by necessity - to focus their students' attention more on the test, sometimes at the expense of other areas of education. While at the same time there has been an increase and focus on the number of experiential learning opportunities, students are seeing the pressures of the bar exam, and letting seats go empty in these opportunities. ${ }^{106}$

The concern relating to professional education is the ability to fit new courses into an already packed schedule, as well as the incentive for students to enroll in courses other than those appearing on the bar exam. Even though the experiential education movement has long gained traction in legal education, and resulted in a requirement for graduation by the ABA, students are passing on experiences that eat up too many credits of their legal education time. Looking at the struggle to engage students in experiential education - can an elective professionalism curriculum now compete in this field?

The answer is possibly not, but the answer also does not lie in making such a professionalism curriculum mandatory. Because of the pressure of the bar exam, students have so little room left in their course of study outside of bar preparation that without a change to that pressure, it is impossible for many schools to add any more to it. The ABA requires 83 credit hours for graduation, while many law schools may require more than that. ${ }^{107}$ The following chart represents a hypothetical Florida law school student's credit allocation in a school that requires 90 credits to graduate - if, because of the pressures of the bar exam, they took all

106. A recent summit between the Deans of Florida law schools, The Florida Bar and the Florida Supreme Court established this factually throughout the state.

107. ABa Standards and Rules of Procedure For Approval of Law Schools, supra note 94 , standard 311 (a), at 21 . 
available courses aligned with the $\mathrm{MBE}$ and the state specific portion of the test, as well as other $A B A$ required courses, and other courses required for graduation. Where there is an " $X$ " it posits no additional credit hours taken, either because the subject overlaps with a course from school to school. ${ }^{108}$

Bar Subject

MBE: Civil Procedure

MBE: Const. Law

MBE: Contracts

MBE: Crim. Law Crim. Proc.

MBE: Evidence

MBE: Real Property

MBE: Torts

FL: UCC: Article 3

FL: UCC: Article 9

FL: Business Entities

FL: Crim. Law

FL: Civil Proc.

FL: Crim. Proc. Rules

FL: Federal Const. Law

FL: Const. Law

FL: Contracts

FL: Evidence

FL: Family Law and Dependency

Juvenile Delinquency

Prof. Resp. - Ch. 4 \& 5

Professionalism

Bar Subject

\section{Course}

Civil Proc.

Const. Law I

Const. Law II

Contracts

UCC: Sales

and Crim. Law

Crim. Proc.

Evidence

Property

Credit
Hours
4
4
3
4
2
4

3

4

4

Real Estate Transactions

Torts

Negotiable Instruments

Secured Transactions

Business Entities

Nonprofit Organizations

Florida Const. Law

$\mathrm{X}$

3

$\mathrm{X}$

Family Law

$\mathrm{X}$

3

Dependency

Juvenile Law

2

3

$\mathrm{X}$

X

Credit

Hours

108. This concept and chart was developed for and by Vision 2016, the Florida Bar's Commission studying the future of the legal profession. See FLA. BAR VISION 2016 COMM'N, FLA.
BAR VISION 2016 REPORT (2016). 
FL: Real Property

FL: Torts

Medical Malpractice

Remedies

Trusts and Wills and Wills and Trust

Administration of Estates

MPRE Exam

Exam Prep Generally

Upper Level Writing

Requirement

First Year Legal Writing Requirement

ABA Exp. Learning

Total

Professional Responsibility 3

FL and Multistate Lab 3

Various courses including 2

seminars, or independent research or law review paper

Legal Research and Writing

Various workshops, clinics and field placements (3-6 credits/Full time would be 12 credits)

As is evident, if a student were to enroll in all the courses that assist them in preparing for The Florida Bar Exam, as well as a minimum of experiential requirements (not including a full semester clinical experience), they would have to take 91 credit hours, without choosing any other electives or experiential learning. Not only would a student following this common schedule only experience $7 \%$ of their credits as experiential learning - a place where professionalism education is already embedded - but implementing an additional professionalism curriculum is truly an impossible task. The answer cannot lie in taking more credits per semester, as ABA Standards prohibits student from taking more than $20 \%$ of the required credits for graduation in any one semester (a cap of 18 each semester). ${ }^{109}$ The only ways to find room in the schedule is either to increase the number of graduation credits- thus paving the way for the $20 \%$ cap to raise - or to reduce the number of subjects students are required to memorize and regurgitate on a standardized test to allow for other kinds of education to fully prepare students for careers and lives as attorneys. The latter choice is clearly the better option.

The Florida Bar recently completed the work of its commission, Vision 2016, a comprehensive look at the future of the legal profession, and has recommended this reduction of subjects to no more than can be taught in two years of legal education, in essence, freeing the equivalent

109. ABA Standards and Rules of Procedure for Approval. of LaW Schools, supra note 94 , standard 311 (c), at 21 . 
of an entire third year for other kinds of learning. ${ }^{110}$ While no changes in the Bar exam can happen without an order from the Florida Supreme Court, such as stance is an important one by that organization and should be one that is considered nationwide.

\section{Cultural}

Perhaps the biggest, yet most intangible obstacle to enacting a professionalism education program is a cultural bias in the legal profession, including legal education, against professionalism, professional identity and other so called "soft skills" pervading a curriculum. This major obstacle is not financial or regulatory-it is the attitude and belief of the decision makers in considering this type of education a priority in preparing students for the profession. The culture of lawyers hasn't caught up with the idea of professionalism as an essential part of legal education.

The culture of legal education against these changes is reinforced by the existence of other obstacles - implementing expensive changes that are not preparing students for Bar exams that require memorization of large numbers of doctrinal subjects simply is not enticing to law faculty. But legal educators must not defend these wrongful attitudes towards teaching professionalism but rather challenge them. Hiring faculty and administration with a demonstrated commitment to professionalism education will slowly chip away at that barrier.

Education of the educators is needed to enact a seismic shift in attitudes of those already there. This type of intermediate education may be a necessary first baby-step to bringing those who educate in line with understanding the crisis and how to solve it, so that effective preventative measures can begin for the next generation. Those faculty decision makers who may already believe in professionalism education but feel reluctance at changes to status quo of legal education curriculum, or are daunted by the obstacles, must not be afraid to take the leap and be leaders in what is right for future generations of lawyers.

\section{Conclusion}

The word crisis has several definitions. It can be "a time of intense difficulty, trouble, or danger," or "a time when a difficult or important decision must be made" as well as "the turning point of a disease when an important change takes place, indicating either recovery or death." 111

110. FLA. BAR Vision 2016 COMM'N, supra note 108.

111. Crisis, Google, https://www.google.com/webhp?sourceid=chrome-instant\&ion=1\& espv $=2 \&$ ie $=$ UTF-8\#q= crisis (last visited June 22,2016 ). 
All three definitions apply to the state of the legal profession and our state of health regarding professionalism. We have a professionalism crisis. The public health of the profession is at stake, and we have the means to develop a vaccine. There is no excuse not to do so. Unlike medical vaccinations, where laws governing vaccines must account for religious exemptions or even philosophy exemptions ${ }^{112}$ no such restriction exists on implementing professionalism education, other than inertia.

The time for hand-wringing and complaining about the behavior of the profession must be finished - the time for change must be upon us. The problem, despite increasingly levels of reactionary cures, continues to escalate. This public health crisis must be solved by going to the root of the problem and reaching new lawyers in their earliest states of formation before the disease can grow. Our multi-point vaccine must include professionalism education, professional identity education, ethics education, stress and time management education, as well as other means of giving new lawyers the tools to fight off the infection of unprofessional conduct. Booster shots, in the form of continuing legal education, continued participation as attorneys in the training and educating of new lawyers, and continued modeling can keep the profession healthy for an entire lawyer's career. We are able to enact this public health indoctrination and we need to do so immediately.

112. States with Religious and Philosophical Exemptions from School Immunization Requirements, NAT'L CONF. OF ST. LEGIS. (Aug. 23, 2016), http://www.ncsl.org/research/health school-immunization-exemption-state-laws.aspx (last visited June 22, 2016). 